\title{
Synthesis of gasoline-range hydrocarbons from nitrogen-rich syngas over a Mo/HZSM-5
}

\section{bi-functional catalyst}

\author{
Yongwu Lu ${ }^{\mathrm{a}, \mathrm{b}}$, Jin $\mathrm{Hu}^{\mathrm{b}}$, Jun Han ${ }^{\mathrm{a}}$, and Fei Yu ${ }^{\mathrm{b}, *}$ \\ ${ }^{a}$ Hubei Key Laboratory of Coal Conversion and New Materials, Wuhan University of \\ Science and Technology, Wuhan 430081, China \\ ${ }^{\mathrm{b}}$ Department of Agricultural and Biological Engineering, Mississippi State University, \\ Mississippi State, MS 39762, USA
}

* Corresponding Author at: Department of Agricultural and Biological Engineering, Mississippi State University, 130 Creelman Street, Mississippi State, MS 39762, USA

Telephone: +1 662-325-3280. Fax: +1 662-325-3853. E-mail: fyu@abe.msstate.edu (F. Yu). URL: http://fy29.abe.msstate.edu (F. Yu).

Keywords: Hydrocarbons; Syngas; Mo/HZSM-5; Bi-functional catalyst; Coke deposition

\begin{abstract}
The production of gasoline-range hydrocarbons from nitrogen-rich syngas was studied over a Mo/HZSM-5 bi-functional catalyst in a bench-scale continuous stainless steel fixed-bed reactor with different reaction conditions. The reaction conditions, i.e., temperature, pressure, and gas hourly space velocity (GHSV), significantly affected the hydrocarbon selectivity. Mo/HZSM-5 was more active in a temperature zone between 350 and $380{ }^{\circ} \mathrm{C}$, a reaction pressure of $1000 \mathrm{psig}$, and a GHSV of $600 \mathrm{~h}^{-1}$ within the test operation condition ranges that were used. More than 20 hydrocarbons were mainly identified from the oil phase sample and can be classified as iso-paraffin, aromatic and naphthene hydrocarbons. The carbon number of the oil sample from the nitrogen-rich syngas mainly contained $\mathrm{C}_{8}-\mathrm{C}_{10}$ hydrocarbons. A high content of nitrogen in syngas was found to have an effect on the liquid hydrocarbon distribution over the Mo/HZSM-5 catalyst.
\end{abstract}




\section{Introduction}

In order to provide alternative solutions to the globally increasing energy shortage and environmental issues caused by the extensive burning of fossil fuels, much effort have been dedicated to developing additional sources of transportation fuels. One such consideration is the conversion of carbonaceous solids (coal, petroleum coke and biomass) and natural gas into high quality, clean-burning transportation fuel [1,2]. The most common methods for production of liquids from carbonaceous solids and natural gas start by first converting the feedstock to a mixture of carbon monoxide and hydrogen called synthesis gas (or syngas) [1]. This can be accomplished by partial oxidation and/or reforming reactions in gasification and reforming unit. Subsequently, syngas can be converted into liquid fuels such as, hydrocarbons and oxygenates [3]. The most common technologies for converting syngas into liquid fuels incorporate Fischer-Tropsch (FT) process or the combination of methanol synthesis and methanol-to-gasoline (MTG) process [3,4].

A continuous biomass to liquid (BTL) via biomass gasification and Fischer-Tropsch synthesis (FTS) process has been developed in Mississippi State University [5] to produce gasoline, diesel and jet fuel ranged hydrocarbons from biomass. This process has gained attention in recent years due to its potential to produce renewable, clean liquid fuels as well as value added chemicals. In this process, biomass (e.g., wood) is first gasified with air to produce raw biomass-derived syngas (bio-syngas using a downdraft gasifier). The reaction in biomass gasification is described by Eq. (1):

$$
\text { Biomass }+\mathrm{O}_{2} \rightarrow \mathrm{CO}, \mathrm{CO}_{2}, \mathrm{H}_{2} \mathrm{O}, \mathrm{H}_{2}, \mathrm{CH}_{4}+\text { other } \mathrm{CHs}+\text { tar }+ \text { char }+ \text { ash }
$$

After gasification, a cleaning process is applied to the raw bio-syngas to remove contaminants like small char particles, ash, and tar in order to meet the synthesis requirements for the catalytic reactor to produce renewable liquid fuels. The conventional FTS catalysts such as Fe-, Co-, and Ru-based catalysts have been extensively studied in 
literature [6]. FTS is the core of gas-to-liquids (GTL) technology. The traditional FTS process produces a wide range of hydrocarbons $\left(\mathrm{C}_{1}-\mathrm{C}_{60}\right)$ production [7], a non-selective formation of hydrocarbons that follows the Anderson-Schulz-Flory (ASF) distribution [8]. Several mechanisms have been proposed for the traditional FTS (e.g., the oxygenate mechanism and the surface carbide mechanism) [9]. The general catalytic reactions in FTS are described in Eq. (2) [10], the $-\mathrm{CH}_{2}-$ group indicates a link of higher hydrocarbon molecule, such as paraffins and olefins.

$$
\mathrm{CO}+2 \mathrm{H}_{2} \rightarrow \frac{1}{n}\left(\mathrm{CH}_{2}\right)_{n}+\mathrm{H}_{2} \mathrm{O}
$$

It is acknowledged that these synthetic linear hydrocarbons from FTS must be further hydrocracked and isomerized to branched, light hydrocarbons in order to obtain high quality synthetic gasoline as transportation fuels [11]. Therefore, much effort has been dedicated to developing novel bi-functional catalysts which are supposed to convert syngas into a selective target of liquid fuel-range hydrocarbons, such as high octane gasoline $\left(\mathrm{C}_{5}-\mathrm{C}_{12}\right)$, in one-step so as to reduce the capital investment [12-14]. There have been many studies that demonstrated the advantages of a one-step with bi-functional catalysts, and comparisons between it and two-step or three-step GTL technology [15-18].

An alternative commercially proven route for converting syngas to liquid fuels is through the conversion of methanol to gasoline (MTG) [19]. MTG selectively converts methanol to liquid product: a very low sulfur, low benzene regular octane gasoline, which can be a valuable blending component for meeting environmental regulations specific to sulfur and benzene [19]. Simultaneous synthesis of methanol from syngas (over the metallic function) and transformation of methanol into hydrocarbons (over the acidic function) can also be done with bi-functional catalysts. The one-step process can promote a change in the thermodynamic equilibrium of methanol synthesis and high shape selectivity of the acidic function which is not possible in the traditional FTS [20]. A mechanism by which a bi- 
functional catalyst works is described in Eqs. (3-6) [19]. Methanol is first dehydrated to dimethyl ether (DME). Then an equilibrium mixture of methanol, DME and water is converted to light olefins $\left(\mathrm{C}_{2}-\mathrm{C}_{4}\right)$ [19]. A final reaction step leads to the synthesis of higher olefins, n/iso-paraffins, aromatics and naphthenes. The shape selective MTG catalyst limits the hydrocarbon synthesis to $\mathrm{C}_{10}$ and lighter [19].

Methanol synthesis:

$$
\mathrm{CO}+2 \mathrm{H}_{2} \leftrightarrow \mathrm{CH}_{3} \mathrm{OH}
$$

Water-Gas-Shift reaction:

$$
\mathrm{CO}+\mathrm{H}_{2} \mathrm{O} \leftrightarrow \mathrm{CO}_{2}+\mathrm{H}_{2}
$$

Hydrocarbons synthesis (Gasoline range):

$$
\mathrm{CH}_{3} \mathrm{OH} \rightarrow \frac{1}{n}\left(\mathrm{CH}_{2}\right) \mathrm{n}+\mathrm{H}_{2} \mathrm{O}
$$

Methane synthesis:

$$
\mathrm{CO}+3 \mathrm{H}_{2} \rightarrow \mathrm{CH}_{4}+\mathrm{H}_{2} \mathrm{O}
$$

Molybdenum (Mo) has been investigated for its catalytic ability for alcohol synthesis [21,22] and methane aromatization [23,24]. Zeolites are powerful in cracking/isomerization of hydrocarbons due to their unique shape selectivity and acidity, and the intrinsic cracking rate of linear hydrocarbons increase with the carbon number [24]. Zeolites, such as HZSM-5, have been used for transforming methanol to gasoline [25] by making use of their shapeselective features. Those features limit chain growth resulting in the formation of lighter hydrocarbons because they inhibit the formation of products larger than the size of the zeolites channels. The acidity of zeolites can catalyze secondary cracking, isomerization, and aromatization reactions of the linear hydrocarbons. The acid sites adjust the final product distribution into a narrow range of fuel, such as the gasoline range hydrocarbons [26]. Therefore, the combination of an alcohol synthesis catalyst with an acidic MTG catalyst, typically a zeolite, into a bi-functional catalyst system such as Mo/HZSM-5, may increase the 
selectivity of gasoline-range hydrocarbon with enhanced nonlinear hydrocarbon content to improve the octane quality.

Generally, syngas derived from the natural gas partial oxidation and/or reforming reactions with air in gasification and reforming units contains high content of nitrogen (50-60 vol.\%) [27]. The use of nitrogen-rich syngas (50-60 vol.\%) could be an alternative to classical processes with nitrogen-free syngas because the investment costs are probably lower, which eliminates the need for an air separation plant, and a process with nitrogen-rich syngas does not utilize a recycle loop and recycle compressor [27]. In addition, the nitrogen in syngas plays a significant role by helping to remove the large amount of heat generated by the catalytic conversion reaction [27]. The Mo/HZSM-5 catalyst system has been used into many reactions [28-30], however, the catalytic conversion of nitrogen-rich syngas into gasoline range hydrocarbons using Mo/HZSM-5 (especially the effects of operation parameters on catalytic performance) has not been extensively studied. Therefore, it is very important to investigate the nitrogen effect on the catalytic performance over Mo/HZSM-5 before using clean biomass-derived syngas, because the biomass-derived syngas (using air as the gasifying agent) also contains high content of nitrogen (50-60 vol.\%),

This study aims to investigate the effects of specific reaction conditions i.e., temperature, pressure, and GHSV on the catalytic performance of the Mo/HZSM-5 catalyst using nitrogen-rich syngas, in order to gain understanding of its behavior in thermochemical catalytic conversion of nitrogen-rich syngas to gasoline range hydrocarbon. The nitrogen-rich syngas used in this study composed of $20 \% \mathrm{CO}, 20 \% \mathrm{H}_{2}$ and $60 \% \mathrm{~N}_{2}$. This gas mixture simulates a typical cleaned bio-syngas composition from a downdraft gasifier with ambient air as the gasifying agent [31-33]. The catalytic performance of the bi-functional catalysts was examined in a stainless steel fixed bed reactor system. The fresh and spent Mo/HZSM-5 catalysts were characterized by using the following methods: Nitrogen 
Adsorption/Desorption BET Surface Area Analysis, Thermo Gravimetric Analyzer (TGA), powder X-ray Powder Diffraction (XRD), Scanning Electron Microscopy (SEM) with Energy-Diffusive X-ray Spectroscopy (EDS), and Transmission Electron Microscopy (TEM).

\section{Experimental}

\subsection{Catalyst preparation}

All Mo/HZSM-5 catalysts used in this study were prepared by using the wetness impregnation method. $\left(\mathrm{NH}_{4}\right)_{6} \mathrm{Mo}_{7} \mathrm{O}_{24} \cdot 4 \mathrm{H}_{2} \mathrm{O}$ was purchased from Fisher Scientific (Pittsburgh, PA). The ammonium form of ZSM-5 $\left(\mathrm{SiO}_{2} / \mathrm{Al}_{2} \mathrm{O}_{3}=50\right)$ was purchased from Zeolyst International (Conshohocken, PA), and was calcined in air at $500{ }^{\circ} \mathrm{C}$ for $20 \mathrm{~h}$ to form HZSM-5 before preparing the bi-functional catalyst. An aqueous solution of $\left(\mathrm{NH}_{4}\right)_{6} \mathrm{Mo}_{7} \mathrm{O}_{24}$ $.4 \mathrm{H}_{2} \mathrm{O}$ and HZSM-5 were physically mixed to form a $5 \mathrm{wt} . \%$ loading of molybdenum. Then the solution was dried in the oven at $120{ }^{\circ} \mathrm{C}$ for $16 \mathrm{~h}$. The mixture was calcined in the oven at $500{ }^{\circ} \mathrm{C}$ for $3 \mathrm{~h}$ and then pelletized without binder into $0.5-1 \mathrm{~mm}$ particles for a catalytic performance test.

\subsection{Catalyst testing and liquid sample analysis}

The catalytic activity test of the Mo/HZSM-5 catalyst was carried out with a bench-scale stainless steel fixed bed tubular reactor under various operation conditions (Fig. 1). Gas lines between the gas cylinders and mass flow controllers were made from $1 / 8$ " copper tubing. The remainder connections of with tubular reactor were made with $1 / 4$ " stainless steel tubing. The tubular reactor was made from a $1 / 2$ " stainless steel tubing with an internal diameter of 0.34'. The catalyst bed was positioned in the middle of the tubular reactor. A thermocouple was placed in the catalyst bed for the reaction temperature monitoring. The reactor was heated with a vertical split tube furnace (Carbolite, Model VST 12/200, Watertown, WI) that had a maximum heating ability of $1200^{\circ} \mathrm{C}$, and a separate control box was attached to control 
the furnace. Three mass flow controllers (Brooks Instrument, Model SLA5850S1BAB1C2A1, Bartlett, TN) connected to a four channel control panel (Brooks Instrument, Model 0254, Bartlett, TN) were used to precisely control the flow rate of inlet gases. All the MFCs were calibrated before the catalytic evaluation tests.

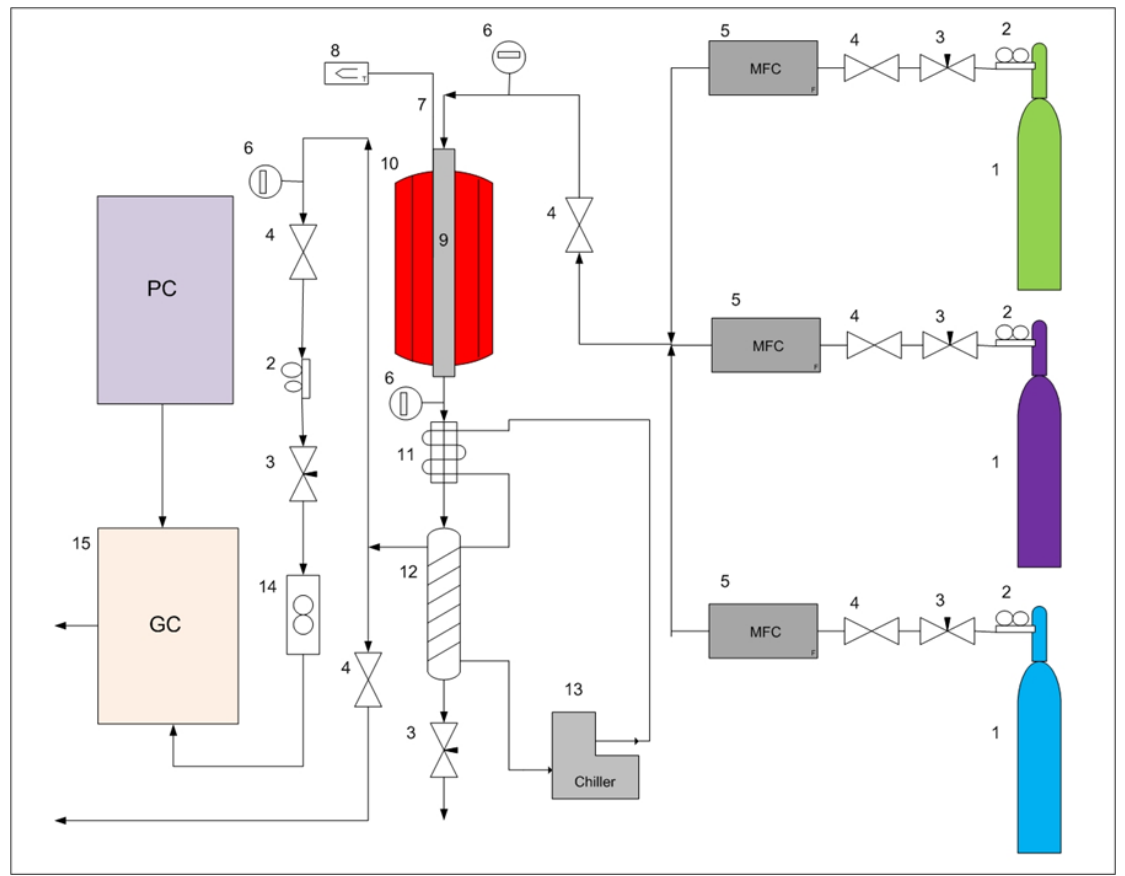

Fig. 1. Schematic drawing of bench-scale stainless steel fixed bed catalytic reactor system.(1) gas cylinders, (2) pressure regulators, (3) needle valves, (4) valves, (5) mass flow controllers (MFCs), (6) digital pressure gauges, (7) thermocouple, (8) thermometer, (9) tubular reactor, (10) furnace, (11) pre-cooling coil, (12) condenser, (13) chiller, (14) mass flow meter, (15) gas chromatograph (GC).

The catalytic activity data was obtained in the absence of mass ad heat transport resistance. Each experimental run used $5.0 \mathrm{~g}$ of pelletized Mo/HZSM-5 catalyst in the catalyst bed. Both ends of the reactor were filled with glass wool to keep the catalyst in the middle of reactor. The catalyst was pre-reduced in-situ at $350{ }^{\circ} \mathrm{C}$ and at atmospheric pressure for $12 \mathrm{~h}$ by using $50 \% \mathrm{H}_{2} / 50 \% \mathrm{CO}$ (mol.) mixture. After that, the pre-mixed nitrogen-rich 
syngas $\left(20 \% \mathrm{H}_{2}, 20 \% \mathrm{CO}\right.$ and $\left.60 \% \mathrm{~N}_{2}\right)$ was fed into the reactor to begin the reaction at the designated operation settings. The catalytic evaluation test was carried out at the desired temperature and pressure after achieving the steady-state for $24 \mathrm{~h}$. The off-gas from the reactor was analyzed by an on-line GC (Agilent, Model 6890, Santa Clara, CA), which was equipped with a thermal conductivity detector (TCD). Liquid samples from the condenser of the reactor system were analyzed off-line with a GC-MS (Agilent Model 6890N, Santa Clara, CA). The GC and GC-MS were calibrated by using an ASTM calibration mixture (ASTM D2887, ASTM D3710, and ASTM D5580) and pure compounds that were purchased from Chiron (Trondheim, Norway). All data were collected and the mean values of three replicates were reported.

The CO conversion and the product selectivity were calculated according to Eqs. (7) and (8), respectively, where $F^{0}$ and $F$ are the flow rates of the inlet syngas and effluent gas, respectively, $C_{i}^{0}$ and $C_{i}$ are the concentrations of component $i$ in the syngas and effluent gas, and $n$ is the carbon number in component $i . \mathrm{N}_{2}$ was used as the internal standard.

$$
\begin{aligned}
& \text { CO conversion }(\%)=\frac{F^{0} C_{C O}^{0}-F C_{C O}}{F^{0} C_{C O}^{0}}=\frac{C_{C O}^{0}-C_{N_{2}}^{0} C_{C O} / C_{N_{2}}}{C_{C O}^{0}} \times 100 \% \\
& \text { Product selectivity }(\%)=\frac{n F C_{i}}{F^{0} C_{C O}^{0}-F C_{C O}}=\frac{n C_{N_{2}}^{0} C_{i}}{C_{N_{2}} C_{C O}^{0}-C_{N_{2}}^{0} C_{C O}} \times 100 \%
\end{aligned}
$$

\subsection{Catalyst characterization}

The morphology of the fresh and spent Mo/HZSM-5 catalyst was studied by using a JEOL JSM-6500F Field Emission Scanning Electron Microscope (Waterford, VA), which included X-EDS and WDS spectrometers and Oxford Instruments INCAEnergy+ software for electron beam-induced X-ray elemental analysis. The EDS analysis was run without standard calibration. 
The catalyst particle sizes and their distribution were investigated by using a JEOL JEM100CX II Transmission Electron Microscope (Waterford, VA) that operated at an accelerating voltage of $100 \mathrm{kV}$.

The BET surface area of the fresh and spent catalysts was measured for nitrogen adsorption/desorption by using a Quantachrome ChemBET PULSAR apparatus. Prior to the BET test, the catalyst was degassed at $150{ }^{\circ} \mathrm{C}$ in the flow of argon. Thermogravimetric Analysis (TGA) using a SHIMADZU TGA-50 was used to determine the thermal properties of catalyst and the amount of coke deposited on the catalyst after undergoing reactions.

The phase composition and crystalline structure of fresh and spent Mo/HZSM-5 catalysts was characterized by X-ray diffraction (Ultima III XRD, Rigaku Americas, The Woodlands, TX) using a $\mathrm{Cu} \mathrm{K \alpha}(\lambda=0.15418 \mathrm{~nm})$ radiation, operated at $40 \mathrm{kV}$ and $44 \mathrm{~mA}$ at a rate of $1^{\circ} \min ^{-1}$, and two theta from $5^{\circ}$ to $90^{\circ}$. The average particle size was calculated according to the Scherrer formula of Eq. (9) using the most intense reflection of crystallites at different values of $2 \theta$,

$$
\mathrm{d}=\left(\frac{0.9 \times \lambda}{B \times \cos \theta_{B}}\right) \times \frac{180}{\pi}
$$

where $d$ was the average crystallite diameter, $\lambda$ was the wavelength of radiation, $\theta_{B}$ was the Bragg angle. $B$ was the line broadening by reference to a standard so that it was represented by Eq. (10),

$$
B^{2}=B_{M}^{2}-B_{S}^{2}
$$

where $B_{M}$ was the full width at half maximum (FWHM) of the diffracted plane of the most intense peak at $2 \theta^{\circ}$, and $B_{s}$ was the full width at half maximum (FWHM: $0.1^{\circ} 2 \theta$ ) of the standard material in radians.

In order to quantitatively analyze the size distribution, the particle size distribution was fitted using the log-normal function shown in Eq. (11) [3]. 


$$
P(\mathrm{D})=\frac{A}{\sigma_{D} \sqrt{2 \pi}} \exp \left(-\frac{1}{2 \sigma_{D}^{2}} \ln ^{2}\left(\frac{D}{D_{0}}\right)\right)
$$

Where $\sigma_{D}$ was the standard deviation of the diameter and $D_{0}$ was the mean diameter.

\section{Results and discussion}

\subsection{Catalyst characterization}

\subsubsection{BET surface area}

The BET surface area of the catalysts was listed in Table 1. The BET surface areas of calcined HZSM-5, fresh Mo/HZSM-5, top, middle and bottom layers of spent HZSM-5 catalyst (after $120 \mathrm{~h}$ running under the reaction condition of $350^{\circ} \mathrm{C}, 1000 \mathrm{psig}$ and GHSV of $600 \mathrm{~h}^{-1}$ ) are $413.7,281.9,177.2,198.4$, and $212.5 \mathrm{~m}^{2} / \mathrm{g}$, respectively. It was observed that the BET surface areas of reacted catalysts were much smaller than the fresh one, and this can be attributed to the slight increase of metal crystallite size during the reaction [34]. Coke deposition on the surface of the catalyst can also cause a smaller surface area to be present on the reacted catalyst [35]. The coke deposited on the surface will cover the active sites and block the zeolite pores. Chen et al. [36] also found that the BET surface area and micro-pore volume decreased after coke was deposited on the catalyst.

Table 1. Physical property of the catalysts.

\begin{tabular}{cccccc}
\hline Sample & $\begin{array}{c}\text { HZSM-5 } \\
\text { (calcined) }\end{array}$ & $\begin{array}{c}\text { Mo/HZSM-5 } \\
\text { (fresh) }\end{array}$ & $\begin{array}{c}\text { Mo/HZSM-5 } \\
\text { (spent top) }\end{array}$ & $\begin{array}{c}\text { Mo/HZSM-5 } \\
\text { (spent middle) }\end{array}$ & $\begin{array}{c}\text { Mo/HZSM-5 } \\
\text { (spent bottom) }\end{array}$ \\
\hline BET surface & \multirow{2}{*}{413.7} & 281.9 & 177.2 & 198.3 & 212.5 \\
area $\left(\mathrm{m}^{2} / \mathrm{g}\right)$ & & & & & \\
\hline
\end{tabular}

\subsection{2. $T G A$}


The thermo-gravimetric analysis (TGA) technique was utilized to study the presence of any volatile and decomposable components and the amount of coke formation after the catalyst reaction using nitrogen-rich syngas. Fig. 2. shows the TGA results for the different layers of used Mo/HZSM-5 catalyst. The results showed that the rapid weight loss began at temperature below $200{ }^{\circ} \mathrm{C}$ and this was attributed to the evaporation of water and hydrocarbon residues formed during the reaction. However, when the temperature went up to around $200{ }^{\circ} \mathrm{C}$, the weight was observed to rise due to the oxidation of the molybdenum species. It has also been observed that the rise of the middle layer was higher than the other two. The coke in the used catalyst started to disappear at temperatures around $380^{\circ} \mathrm{C}$. This result was in agreement with the study done by Li et al. [37].

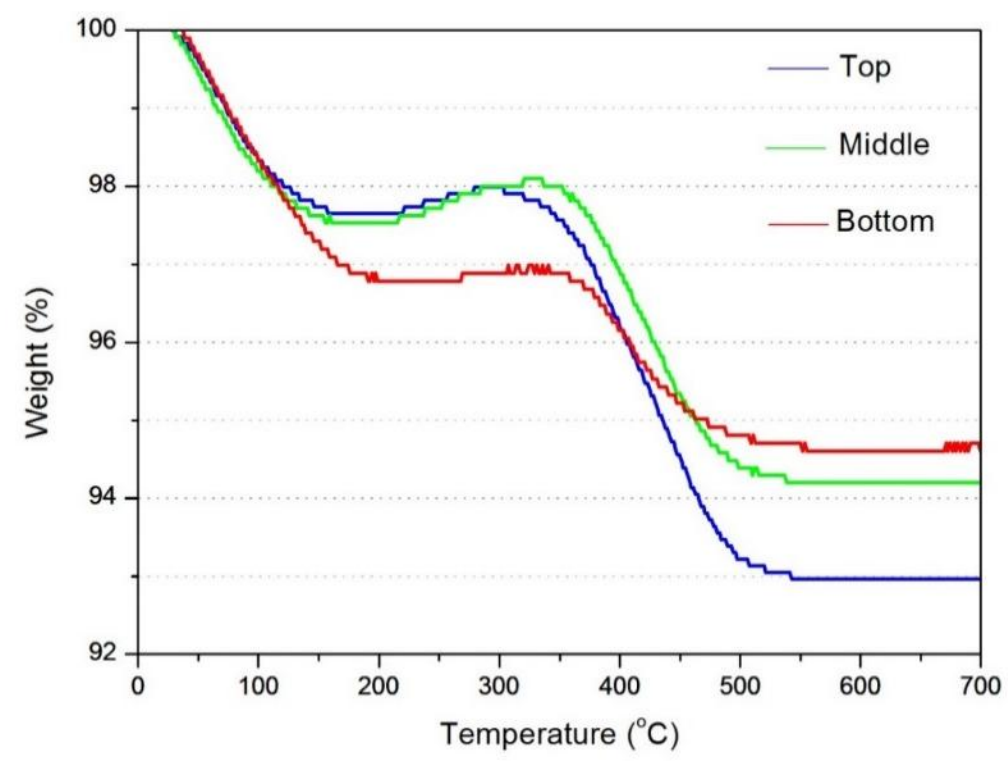

Fig. 2. TGA analysis of different layers of used catalysts.

The weight percentage of coke formed on top, middle and bottle layers of spent catalyst were $3.85 \%, 3.23 \%$ and $1.97 \%$, respectively. The TGA results suggested that the top layer of spent catalyst had most severe coke deposition during the reaction. 


\subsubsection{XRD}

XRD analysis of calcined HZSM-5, fresh and spent Mo/HZSM-5 catalysts are shown in Fig. 3. The diffraction peaks in the calcined HZSM-5 at $2 \theta$ of $7.972,8.818,8.917,9.123$, 23.097, 23.319, 23.719 and 23.949 corresponding to the planes (101), (200), (020), (111), (332), (051), (151) and (303), respectively. The results are in agreement with the previously literatures [38,39] and (JCPDS:44-0003). The diffraction peaks in the fresh Mo/HZSM-5 catalyst at $2 \theta^{\circ}$ of $12.780,23.339,25.699,25.879,27.339,33.119,33.759$, and 38.979 corresponding to the planes (020), (110), (040), (120), (021), (101), (111) and (060), respectively, confirmed the formation of $\mathrm{MoO}_{3}$ which was in agreement with the previous researches [40-42] and (JCPDS:35-0609).

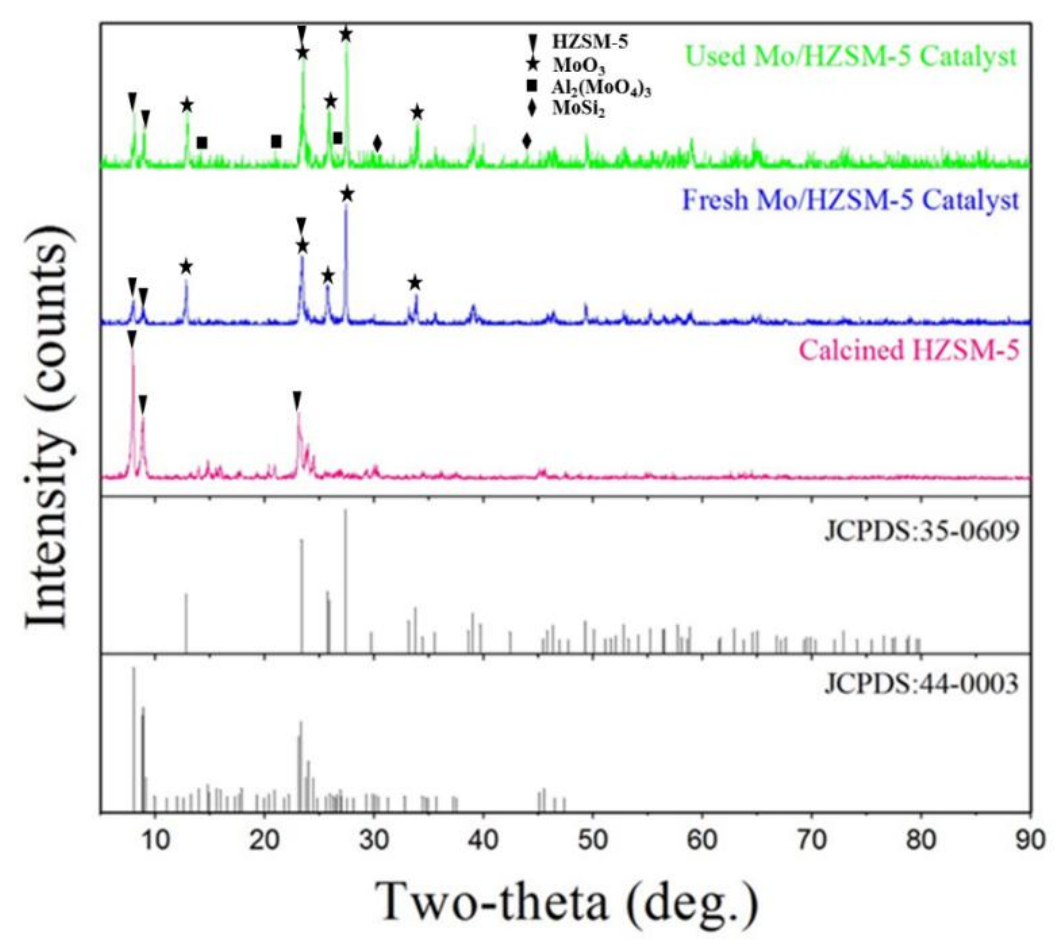

Fig. 3. XRD analysis of calcined HZSM-5, fresh and spent Mo/HZSM-5 catalysts.

The other peaks in fresh Mo/HZSM-5 coincided in position with those of the parent HZSM-5 diffraction pattern. This indicates that the HZSM-5 framework was well preserved 
after impregnation. However, it was also observed that the loading of molybdenum caused a decrease on the HZSM-5 crystallinity since a reduction of the HZSM-5 characteristic peaks was observed. The reason for the decrease in the peaks intensity can be explained by the dispersion of the Mo species into the HZSM-5 channels [43].

The diffraction pattern of spent Mo/HZSM-5 catalyst did not significantly differ from the fresh one which suggested that the structure of HZSM-5 supported molybdenum catalyst was kept almost stable under the reaction environment, and this was in agreement with previous research results $[37,44]$. However, the appearance of the $2 \theta^{\circ}$ at $14.091,20.835$, 23.143 and 26.267 corresponded to the planes (200), (102), (112), and (212) of the aluminum molybdenum oxide (JCPDS: 23-0764). This confirmed the formation of $\mathrm{Al}_{2}\left(\mathrm{MoO}_{4}\right)_{3}$ in the spent catalyst. These characteristics were the evidence of a partial dealumination of the HZSM-5 support. Liu et al. [45] suggested that the dealumination that was derived from a higher interaction between molybdenum species and the framework aluminum of HZSM-5 caused a catalytic activity loss during the reaction. The $2 \theta^{\circ}$ of 30.096 and 44.683 corresponded to the planes (101) and (103) of the molybdenum silicide. This confirmed the formation of $\mathrm{MoSi}_{2}$ in the spent catalyst which was in agreement with previous research [46] and (JCPDS: 41-0612). Thus, the molybdenum species in the spent catalyst were majorly composed of $\mathrm{MoO}_{3}$. $\mathrm{Al}_{2}\left(\mathrm{MoO}_{4}\right)_{3}$ and $\mathrm{MoSi}_{2}$ were also identified in the spent catalyst.

\subsubsection{SEM-EDS}

The SEM images of fresh and spent Mo/HZSM-5 catalyst (top, middle and bottom layers from the reactor) are presented in the Fig. 4. The image of the fresh Mo/HZSM-5 catalyst shows that the catalyst was well distributed as small particles with no obvious agglomeration. The crystallites of the molybdenum species were covered on the surface of zeolite. The spent Mo/HZSM-5 catalyst images showed much more agglomerations than the fresh catalyst. This may be caused by sintering during FTS. There were also tiny spherical 
particles on the surface of the top layer of the spent Mo/HZSM-5 catalyst, this may be due to the aggregation of molybdenum particles on the surface of zeolite. Therefore, the HZSM-5 was uncovered and separated from the coverage of molybdenum crystallites, and then the small catalyst particles agglomerated and grew into larger particles to form agglomerations. This kind of agglomeration can cause the deactivation and deterioration of the catalyst. This phenomenon was also observed by Gallarage et al. [47], which showed that high temperature will cause the agglomeration of the catalyst particles and result in a decrease of the catalytic performance of the catalyst. The agglomeration can also be the result of an inhomogeneous distribution of metal precursors. The small particles observed on the surface of used Mo/HZSM-5 can also be attributed to the coke formation and decomposition during the reaction (EDS analysis).
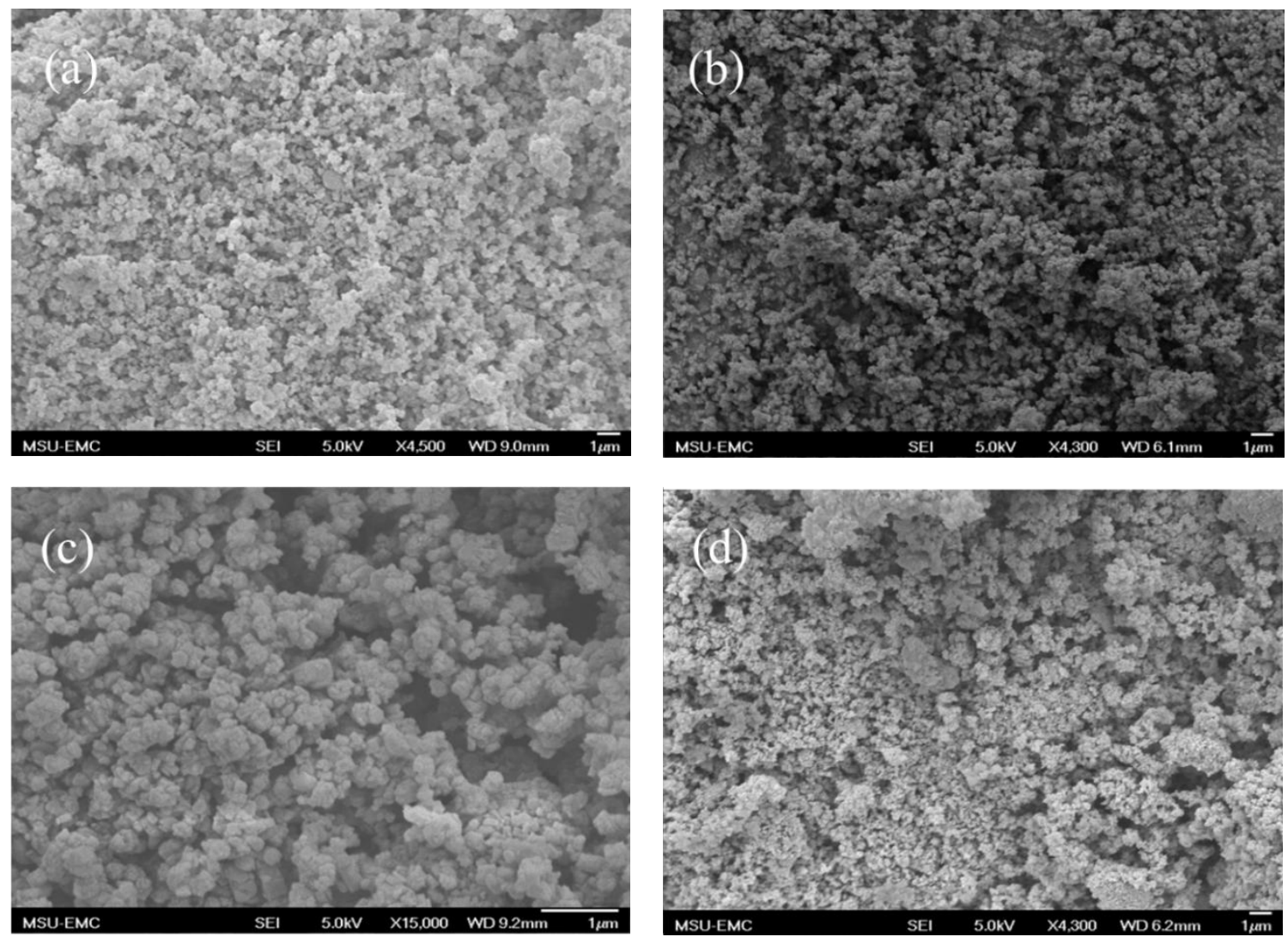

Fig. 4. SEM images of catalysts at different stages. (a) Fresh Mo/HZSM-5 catalyst (b) top (c) middle and (d) bottom layers of used Mo/HZSM-5 catalysts. 
Table 2. Elemental distribution of fresh and used Mo/HZSM-5 catalysts (wt.\%)

\begin{tabular}{cccccc}
\hline \multirow{2}{*}{ Sample } & \multicolumn{5}{c}{ Element } \\
\cline { 2 - 6 } & $\mathrm{C}$ & $\mathrm{O}$ & $\mathrm{Al}$ & $\mathrm{Si}$ & $\mathrm{Mo}$ \\
\hline Fresh Mo/HZSM-5 & 0 & 54.20 & 5.66 & 36.29 & 3.85 \\
Spent Mo/HZSM-5 (top) & 55.58 & 36.97 & 1.21 & 5.75 & 0.49 \\
& & & & & \\
Spent Mo/HZSM-5 (middle) & 38.11 & 37.58 & 3.33 & 18.74 & 2.24 \\
Spent Mo/HZSM-5 (bottom) & 19.87 & 54.40 & 3.71 & 20.14 & 1.88
\end{tabular}

The spent catalysts were observed to have a dark grey color which indicated that carbon was deposited on the catalyst after reaction. Table 2 shows the EDS analysis results for the elemental distribution of fresh and spent Mo/HZSM-5 catalysts. Clearly, coke deposition was most severe in the top layer of the catalyst which had an amount of $55.58 \%$ carbon deposition on the surface of the catalyst. This was in agreement with the BET and TGA results. Typically, there are at least three kinds of cokes of Mo/Zeolite: carbidic carbon in molybdenum carbide, molybdenum-associated coke, and aromatic-type cokes on acid sites of zeolite [48]. Coking on the surface of bi-functional catalysts may cause losses of activity and may lead to a decrease in aromatic product selectivity because of the loss of available acidic sites for the conversion of olefins to aromatics [49]. Some coke deposited into the pores of the zeolite and blocked of the pores. Also, some coke deposited on the acidic sites of the zeolite. These cokes in the zeolite channel maybe pre-graphitic type of carbon, graphitic-like carbon, or aromatic-type carbon [48].

It was suggested that the aromatic-type cokes on Brønsted acid sites were responsible for catalyst deactivation in the methane aromatization reaction, which made diffusion and migration of molecules difficult [48]. The products (benzene, naphthalene, and other bulk aromatics) formed in the supercages (12 ring) had to pass the relatively smaller 10-ring 
window in their migration into and diffusion out of the channels, possibly leaving an aromatic-type coke on the acid sites of these windows with a significant role in the jamming of the zeolite channels [48].

\subsubsection{TEM}

A Jeol JEM-100CXII TEM was used to characterize the Mo/HZSM-5 catalyst. The Mo/HZSM-5 catalyst particle sizes and their distribution before and after reactions were compared in this study. The morphologies and particle size distributions of fresh and spent Mo/HZSM-5 catalyst were shown in Fig. 5. and Fig. 6., respectively.

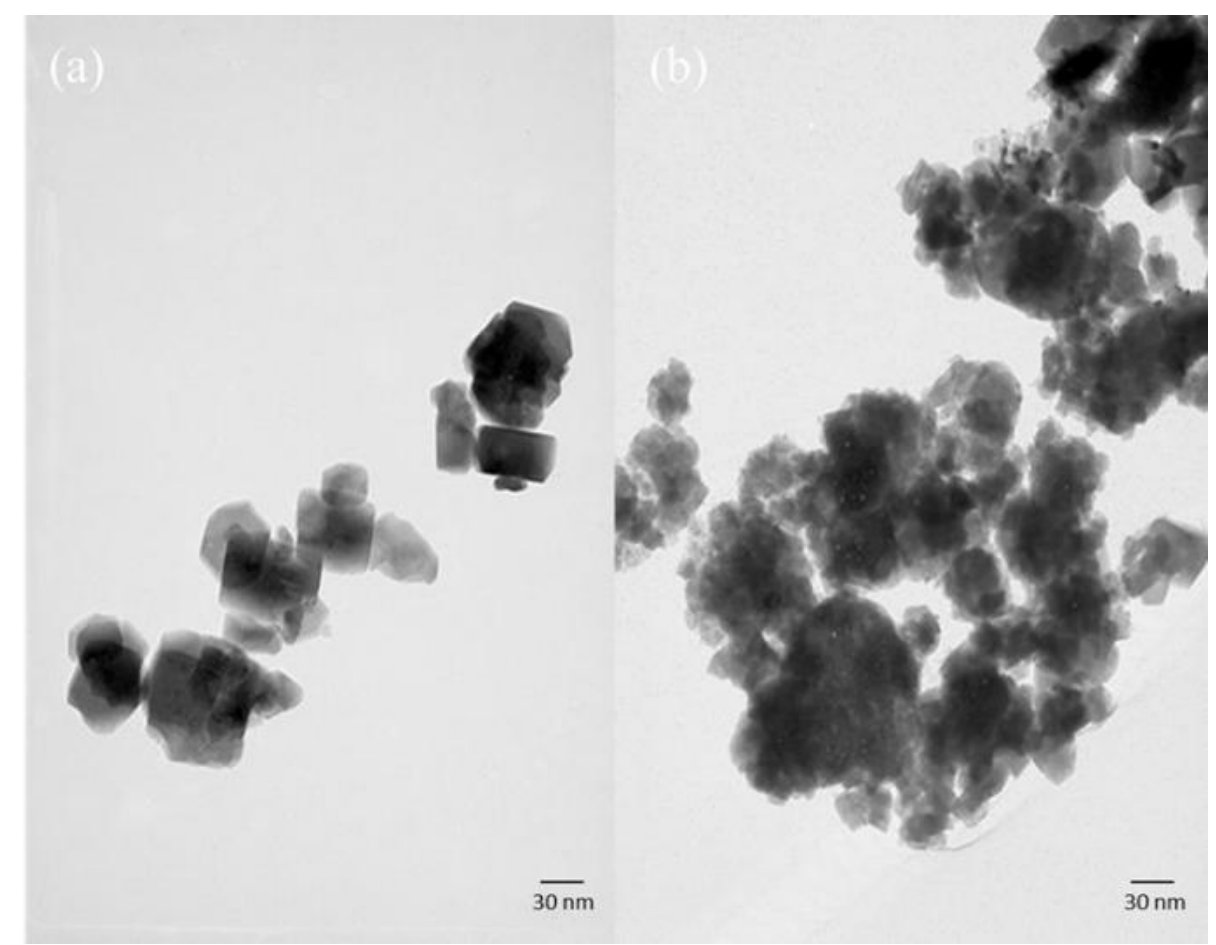

Fig. 5. TEM images of catalysts at different stages. (a) Fresh and (b) top layer of spent Mo/HZSM-5 catalysts. 
(a)

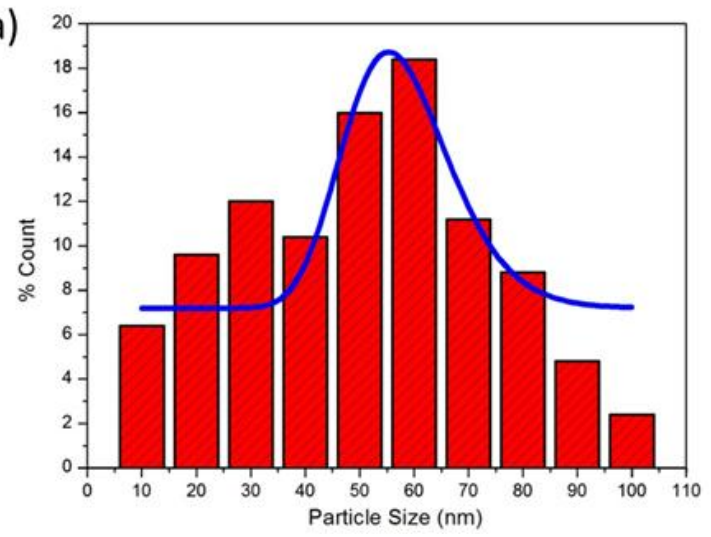

(b)

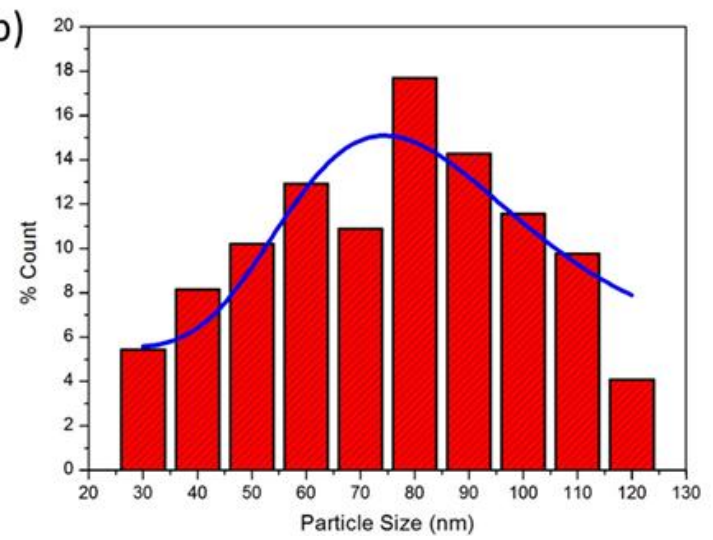

Fig. 6. Particle size distribution and fitted curve for catalysts at different stages. (a) Fresh and (b) top layer of spent Mo/HZSM-5 catalysts.

The fresh Mo/HZSM-5 catalyst particles were well distributed, with a mean diameter $\left(\mathrm{D}_{0}\right)$ of $56.99 \pm 0.17 \mathrm{~nm}$ according to Eq. (11), while the used catalyst showed a larger particle size, with $\mathrm{D}_{0}$ of $80.83 \pm 0.29 \mathrm{~nm}$. This resulted from the high temperature agglomeration of the catalyst. This result also corresponded to the crystallite size calculated from the XRD diffraction pattern using the Scherrer formula [Eq.(9)]. The surrounding of the fresh catalyst was clean and without obvious tiny particles, while plenty of small particles were discovered to be around the spent Mo/HZSM-5. This was attributed to the agglomeration of molybdenum particles and the coke deposition on the surface of the catalyst.

\subsection{Catalytic performance}

The catalytic performance of the bi-functional Mo/HZSM-5 catalyst in the conversion of nitrogen-rich syngas into liquid fuel was investigated. The effects of reaction temperature, pressure and GHSV were studied in the fixed-bed reactor system. The experiments were performed at different temperatures ranging from 300 to $380^{\circ} \mathrm{C}$. The reaction pressure was varied from 500 to $1000 \mathrm{psig}$, and the GHSV was varied from 600 to $2400 \mathrm{~h}^{-1}$. CO conversion 
and product selectivity on a carbon basis were calculated by using Eqs. (7) and (8), respectively.

\subsubsection{The effect of reaction temperature}

The catalytic tests were carried out at the reaction temperatures including 300, 320, 340, 350,360 , and $380^{\circ} \mathrm{C}$. The GHSV and pressure maintained at $600 \mathrm{~h}^{-1}$ and $1000 \mathrm{psig}$, respectively. Fig. 7. (a) shows that $\mathrm{CO}$ conversion varied with the change of the reaction temperature. Generally, the $\mathrm{CO}$ conversion was significantly influenced by temperature, it increased from $12 \%$ at $300^{\circ} \mathrm{C}$ to $65 \%$ at $350^{\circ} \mathrm{C}$. The $\mathrm{CO}$ conversion fluctuated from 350 to $380^{\circ} \mathrm{C}$ and decreased to $63 \%$ at $360^{\circ} \mathrm{C}$ and then increased to $67 \%$ at $380^{\circ} \mathrm{C}$ (which was the highest $\mathrm{CO}$ conversion among the tested temperature range). The $\mathrm{CO}$ conversion increased from 300 to $350^{\circ} \mathrm{C}$. However, it slowed down when reaching higher temperatures after $350^{\circ} \mathrm{C}$. This suggests that although the catalyst was more active at higher temperature, the difference due to temperature was limited because of the thermodynamic limitation and deactivation of the catalyst caused by the sintering of the Mo catalyst at higher temperatures [50].

(a)

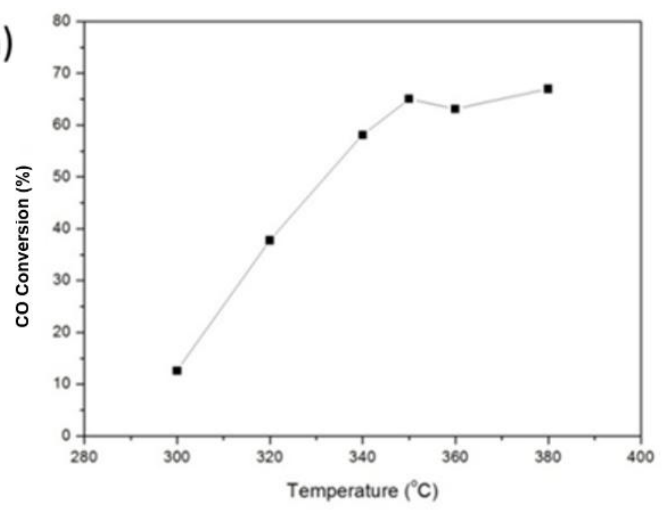

(b)

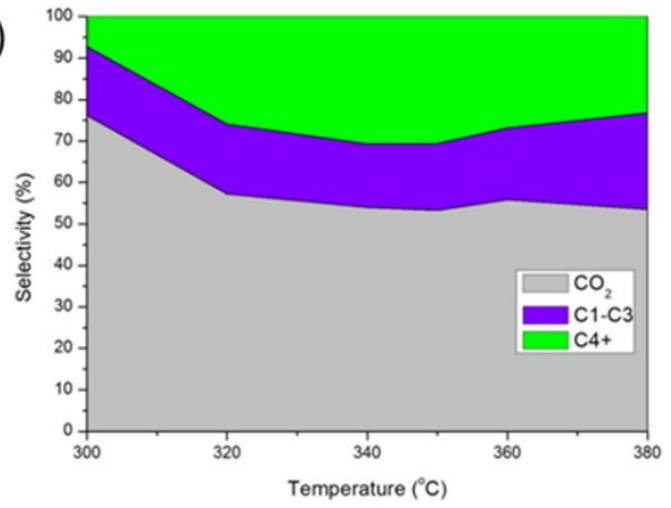

Fig. 7. The effect of reaction temperature on catalytic performance. (a) CO conversion and (b) product selectivity at GHSV of $600 \mathrm{~h}^{-1}$ and $1000 \mathrm{psig}$. 
Fig. 7. (b) shows the product selectivity towards $\mathrm{CO}_{2}$, light hydrocarbons $\left(\mathrm{C}_{1}-\mathrm{C}_{3}\right)$ and higher hydrocarbons $\left(\mathrm{C}_{4}^{+}\right)$. The product selectivity was affected by the change of temperature, and higher hydrocarbons favored a moderate temperature range. Although, the $\mathrm{CO}_{2}$ selectivity decreased as the temperature increased, the $\mathrm{CO}_{2}$ yield showed an increase from $300^{\circ} \mathrm{C}$ to $380^{\circ} \mathrm{C}$. Higher temperatures produced more $\mathrm{CO}_{2}$ which will aggravate the carbon loss and a reduction in utilizing the carbon efficiency. The thermodynamics suggest that only light hydrocarbons $\left(\mathrm{C}_{1}-\mathrm{C}_{3}\right)$ will have stable selectivity at higher temperatures, and the higher hydrocarbons $\left(\mathrm{C}_{4}^{+}\right)$more sensitive to higher temperatures will undergo cracking and de-alkylation reactions at higher temperatures [51]. The selectivity of light hydrocarbons kept increasing among the test temperature range, and achieved $27 \%$ at $380^{\circ} \mathrm{C}$. However, the selectivity of higher hydrocarbons increased from 300 to $350^{\circ} \mathrm{C}$, and then dropped from 350 to $380^{\circ} \mathrm{C}$. The maximum selectivity to higher hydrocarbons was observed to be $31 \%$ at $350^{\circ} \mathrm{C}$. This result corresponded to previous researches on the effect of reaction temperature on catalytic performances of $\mathrm{CO}$ hydrogenation [52,53].

\subsubsection{The effect of reaction pressure}

The catalytic performance tests of the effect of reaction pressure were carried out at 500, 600, 700, 800, 900 and 1000 psig. The GHSV and reaction temperature were maintained at $600 \mathrm{~h}^{-1}$ and $350^{\circ} \mathrm{C}$, respectively. Fig. 8. (a) showed $\mathrm{CO}$ conversion increased with the increase of reaction pressure. CO conversion was significantly influenced by pressure and increased from $28.1 \%$ at 500 psig to $65.1 \%$ at 1000 psig. This was a reasonable result in a condensation process, in which the limiting step of the whole reaction was methanol synthesis. According to the thermodynamics, the pressure increase in the reaction system will push the equilibrium toward the product side and then cause a rise of the CO conversion. 
Generally, the increase of reaction pressure will cause a negative change in Gibbs free energy, so it was an important factor in achieving higher $\mathrm{CO}$ conversion for bi-functional catalysts [54].
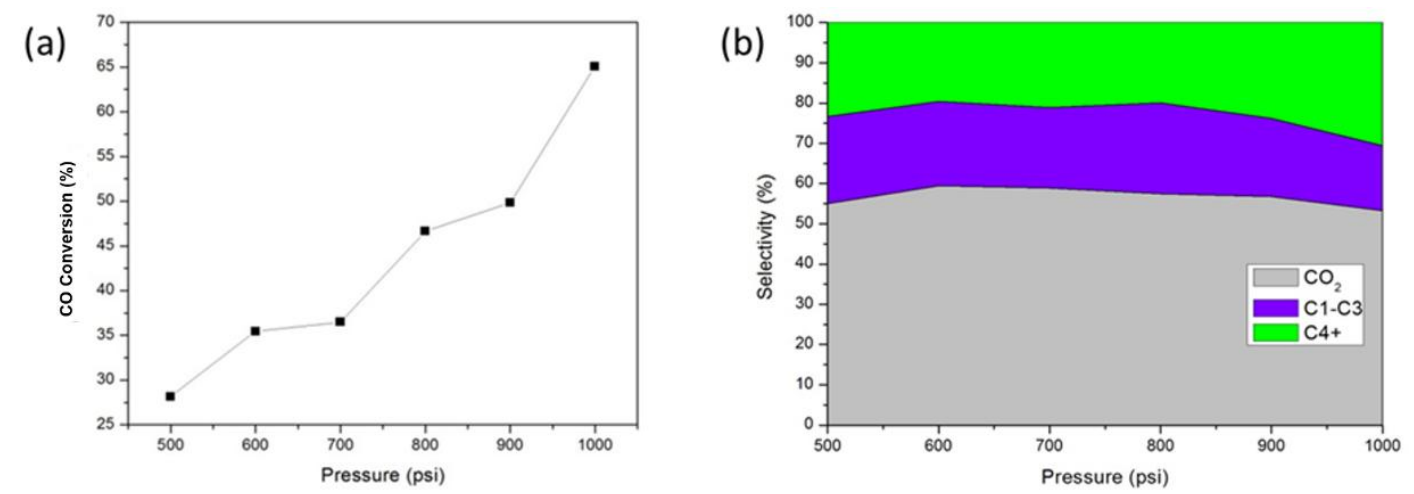

Fig. 8. The effect of reaction pressure on catalytic performance. (a) $\mathrm{CO}$ conversion and (b) product selectivity at GHSV of $600 \mathrm{~h}^{-1}$ and $350^{\circ} \mathrm{C}$.

The total carbon content that was converted from the feed gas into $\mathrm{CO}_{2}$ ranged from $55 \%$ to $60 \%$ in the range of test pressure. Similar to what was shown in Fig. 8 (b), $15 \%$ to $25 \%$ of the carbons were converted into $\mathrm{C}_{1}-\mathrm{C}_{3}$ hydrocarbons while $20 \%$ to $35 \%$ were converted into $\mathrm{C}_{4}{ }^{+}$hydrocarbons. From the reaction pressure of 500 to $600 \mathrm{psig}$, the $\mathrm{CO}_{2}$ selectivity increased slightly from 55\% to $60 \%$. From the reaction pressure of 600 to 1000 psig, it decreased from $60 \%$ to $53.2 \%$. The selectivity to $\mathrm{C}_{1}-\mathrm{C}_{3}$ hydrocarbons remained almost constant and with little change from 500 to 800 psig, but dropped greatly when the pressure increased to 900 and 1000 psig. The selectivity to $\mathrm{C}_{4}{ }^{+}$hydrocarbons showed similar characteristics with the selectivity to $\mathrm{C}_{1}-\mathrm{C}_{3}$ hydrocarbons when the reaction pressure was between 500 and 800 psig.

When the reaction pressure increased from 800 to 1000 psig, the selectivity to $\mathrm{C}_{4}{ }^{+}$ hydrocarbons increased dramatically to $31 \%$. This result should be attributed to the fact that at the lower reaction pressure zone $(<800 \mathrm{psig})$, the selectivity to $\mathrm{C}_{1}-\mathrm{C}_{3}$ and 
$\mathrm{C}_{4}{ }^{+}$hydrocarbon fractions were negligibly affected by the reaction pressure. However, in higher pressure zone (> 800 psig), the condensation reactions were favored (aromatization, oligomerization and alkylation). A high pressure around 1000 psig was better for gasoline range hydrocarbons production because the selectivity to $\mathrm{CO}_{2}$ and $\mathrm{C}_{1}-\mathrm{C}_{3}$ hydrocarbons were both lower than the selectivity in other pressures, and the selectivity to $\mathrm{C}_{4}{ }^{+}$hydrocarbons were the highest around 1000 psig.

\subsubsection{The effect of GHSV}

Fig. 9 (a) showed that the flow rate of syngas had a significant effect on CO conversion. A conversion of $65 \%$ was achieved at a GHSV of $600 \mathrm{~h}^{-1}$ (which was the highest conversion in the test of GHSV range). At $1200 \mathrm{~h}^{-1}$ and $2400 \mathrm{~h}^{-1}$ the CO conversion were $37.4 \%$ and $22 \%$, respectively.
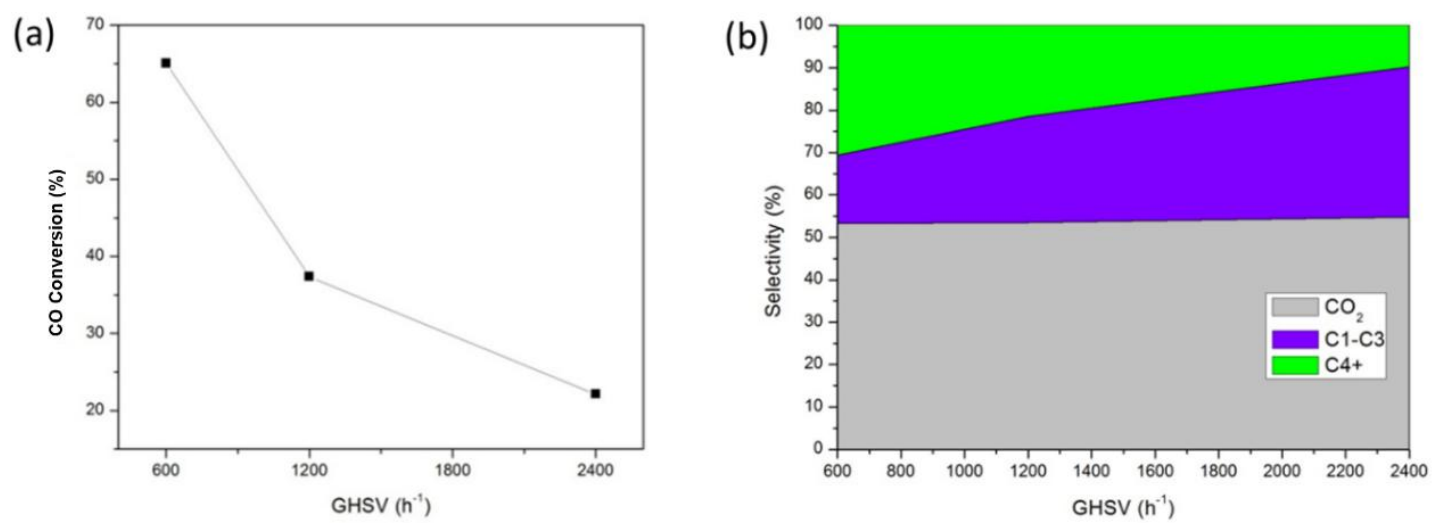

Fig. 9. The effect of GHSV on catalytic performance. (a) CO conversion and (b) product selectivity at $1000 \mathrm{psig}$ and $350^{\circ} \mathrm{C}$.

Fig. 9 (b) showed the effect of GHSV on the product selectivity. The GHSV increased from 600 to $2400 \mathrm{~h}^{-1}$ and selectivity to $\mathrm{CO}_{2}$ only had a slight increase from $53.2 \%$ to $54.8 \%$. The selectivity to $\mathrm{C}_{1}-\mathrm{C}_{3}$ hydrocarbons jumped from $16 \%$ to $35.4 \%$, while selectivity to $\mathrm{C}_{4}{ }^{+}$ hydrocarbons had the opposite behavior (selectivity to $\mathrm{C}_{4}{ }^{+}$hydrocarbons dropped from $30.6 \%$ 
to $9.8 \%$ ). This may be caused by the change of the reaction time of $\mathrm{CO}$ and $\mathrm{H}_{2}$ over the catalyst surface. When the flow rate was slow, $\mathrm{CO}$ and $\mathrm{H}_{2}$ had more time to react with each other, and the hydrocarbon chains would have more probability to propagate to form longer hydrocarbon chains of $\mathrm{C}_{4}{ }^{+}$. When the flow rate increased, the probability to form longer $\mathrm{C}_{4}{ }^{+}$ hydrocarbon chains decreased due to the lack of reaction time, so instead of $\mathrm{C}_{4}{ }^{+}$ hydrocarbons, the reaction would prefer to form $\mathrm{C}_{1}-\mathrm{C}_{3}$ hydrocarbons.

\subsection{Liquid sample analysis}

Liquid samples were collected from the condenser of the reactor system after the catalytic evaluation tests using nitrogen-rich syngas under the conditions of $350^{\circ} \mathrm{C}, 1000$ psig, and GHSV of $600 \mathrm{~h}^{-1}$ for $120 \mathrm{~h}$. GC-MS analysis of the oil phase results showed that more than 20 hydrocarbons were mainly detected as shown in Fig. 10.

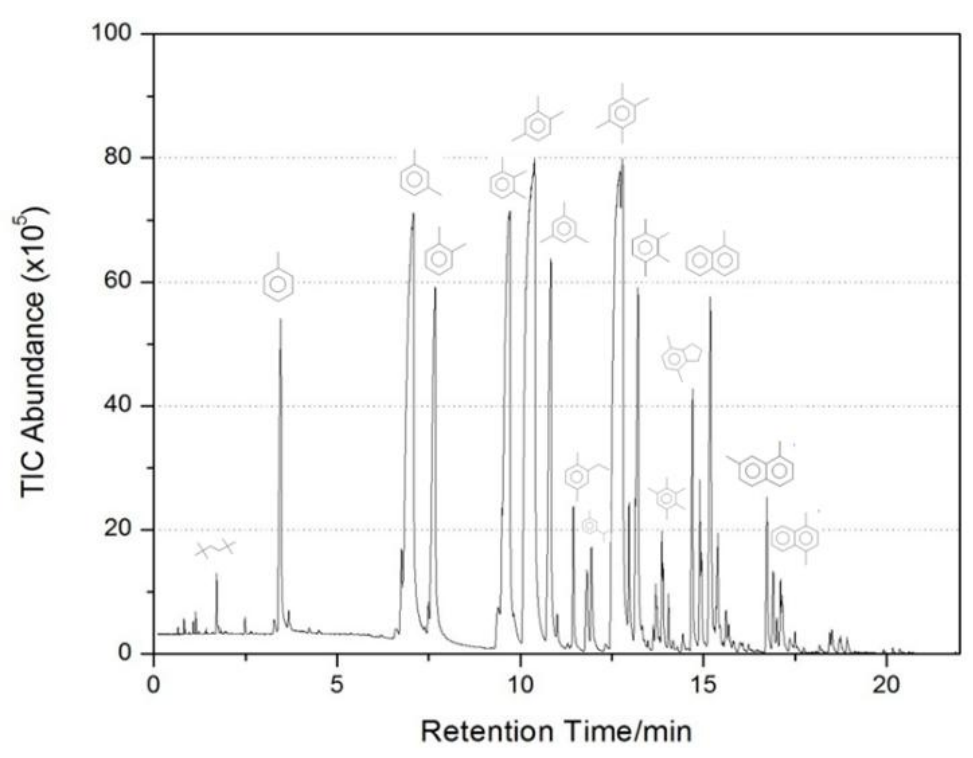

Fig. 10. GC-MS result of the oil phase after the catalytic reaction of $\mathrm{N}_{2}$-rich syngas on the Mo/HZSM-5 catalyst. (Reaction conditions: $350^{\circ} \mathrm{C}, 1000 \mathrm{psig}$, GHSV of $600 \mathrm{~h}^{-1}$ for $120 \mathrm{~h}$ )

The hydrocarbons produced in this study can be grouped into four groups: (a) paraffins (e.g., pentane, hexane, and heptane), (b) iso-paraffins (e.g., iso-butane, 2-Methylbutane and 2, 
4-Dimethylpentane), (c) aromatics (e.g., Benzene, Toluene, Ethylbenzene and Trimethylbenzene), and (d) naphthenes (e.g., 1, 3-dimethyl-cyclopentane and 1, 4-dimethylcyclohexane). Iso-paraffins, aromatics and naphthenes were the major products in the liquid sample. Several selected components and their weight percentage were listed in Table 3.

Table 3. Weight percentage of selected components from liquid sample.

\begin{tabular}{cccccc}
\hline Component & Benzene & Toluene & Ethylbenzene & Xylene & Trimethylbenzene \\
\hline Weight Percentage & 0.17 & 2.72 & 3.31 & 18.1 & 13.65 \\
\hline
\end{tabular}

These results indicated that the Mo/HZSM-5 catalyst was active in the syngas conversion and the catalyst was highly selective to synthesize branched and cyclized alkanes and aromatics. The carbon number of the liquid product generally fell into the $\mathrm{C}_{8}-\mathrm{C}_{10}$ hydrocarbon range (Fig. 11.). This was a reasonable result of abundant iso-paraffin and aromatic hydrocarbon production from Mo/HZSM-5 bi-functional catalyst because hydrocarbons higher than $\mathrm{C}_{11}$ are too large to be formed readily inside the pores of HZSM-5 [55]. Some oxygenates were also detected in the water phase by GC-MS, such as ethanol and acetone. This may be due to the mechanism of conversion of intermediate alcohol to hydrocarbon over the Mo/HZSM-5 catalyst. 


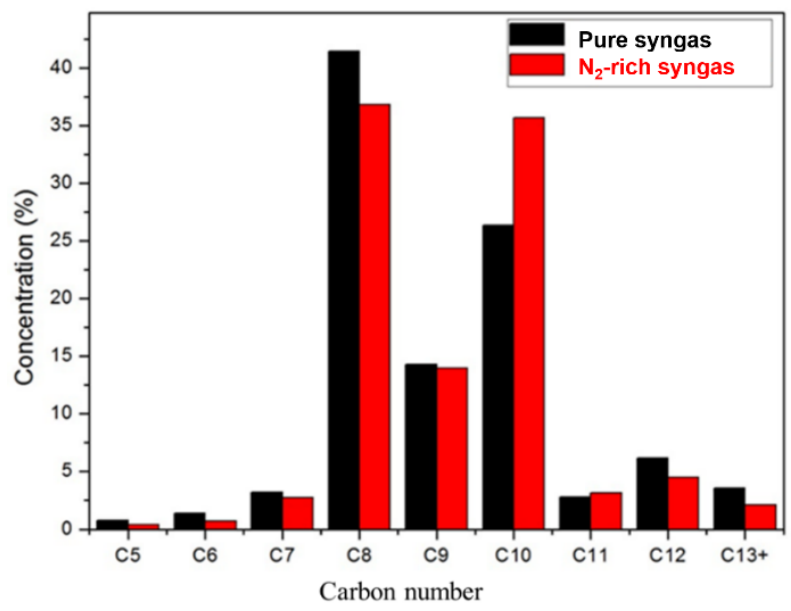

Fig. 11. Comparison of carbon number distribution of oil phase from pure syngas and $\mathrm{N}_{2}$-rich syngas.

\subsection{The effect of nitrogen in the syngas conversion}

Depending on the gasifying oxidants used in the gasification process, the nitrogen content in syngas may vary. When the ambient air was used as the oxidant, the nitrogen content will be around 50-60\% in the raw biomass-derived syngas. The use of ambient air is an inexpensive way of producing syngas and it reduces the capital cost in the gasification process because the preparation of syngas is the capital-intensive part of the process. The presence of nitrogen in the syngas also played a significant role in removing heat generated by the exothermic reactions of FTS [56]. In order to evaluate the effects of nitrogen in the catalytic conversions with the Mo/HZSM-5 catalyst, both pure syngas $\left(50 \% \mathrm{H}_{2}\right.$ and $\left.50 \% \mathrm{CO}\right)$ and nitrogen-rich syngas $\left(20 \% \mathrm{H}_{2}, 20 \% \mathrm{CO}\right.$, and $\left.60 \% \mathrm{~N}_{2}\right)$ were used separately and their performances were compared. The hydrocarbon number distribution of products from pure syngas and nitrogen-rich syngas are shown in Fig. 11.

Both reactions were carried out for $120 \mathrm{~h}$ under a temperature of $350^{\circ} \mathrm{C}$ and a GHSV of $600 \mathrm{~h}^{-1}$. The overall operation pressure differed so that the partial pressure would be the same for $\mathrm{CO}$ and $\mathrm{H}_{2}$. The reaction pressure was 1000 psig for nitrogen-rich syngas and 400 psig for pure syngas. Products distributions from nitrogen-free and nitrogen-rich feed syngas were 
different, especially distributions relating to the $\mathrm{C}_{8}$ and $\mathrm{C}_{10}$ hydrocarbons. Nitrogen-rich syngas produced more $\mathrm{C}_{10}$ hydrocarbons and smaller amounts of $\mathrm{C}_{8}$ hydrocarbons than pure syngas did. This result was different from studies by Jess et al. [27] and Xu et al. [58] on traditional Fischer-Tropsch synthesis. Their research showed that nitrogen only dilutes syngas, and has little influence on the kinetics if the partial pressures of carbons monoxide and hydrogen are kept constant. The difference in product distribution caused by the presence of the high nitrogen content may be attributed to its dilution and removal of reaction heat.

\section{Conclusions}

The production of gasoline-range hydrocarbons from nitrogen-rich syngas was studied by the Fischer-Tropsch synthesis (FTS) over a 5 wt.\% Mo/HZSM-5 bi-functional catalyst using a bench-scale continuous stainless steel fixed-bed reactor. The reaction conditions, i.e., temperature, pressure, and gas hourly space velocity (GHSV), significantly affected the gasoline-range hydrocarbon selectivity using nitrogen-rich syngas. Mo/HZSM-5 was more active in a temperature zone between 350 and $380^{\circ} \mathrm{C}$, a reaction pressure of $1000 \mathrm{psig}$, and a GHSV of $600 \mathrm{~h}^{-1}$ within the test operation condition ranges that were used. More than 20 hydrocarbons were mainly identified from the oil phase sample and can be classified as isoparaffin, aromatic and naphthene hydrocarbons. The carbon number of the oil sample from the nitrogen-rich syngas mainly contained $\mathrm{C}_{8}-\mathrm{C}_{10}$ hydrocarbons. A high content of nitrogen in syngas was found to have an effect on the liquid hydrocarbon distribution over the Mo/HZSM-5 catalyst.

\section{Acknowledgments}

This work was supported by the Department of Energy under Awards (DE-FG3606GO86025, DE-FC2608NT01923), US Department of Agriculture under Award (AB567370MSU). 


\section{References}

[1] W. Lan, G. Chen, X. Zhu, X. Wang, B. Xu. J. Energy Inst. (2014) in press, doi:10.1016/j.joei.2014.05.003.

[2] J. Han, X. He, R. Li, C. Wan, Q. Yan, F. Yu. J. Energy Inst. 87 (2014) 246-252.

[3] Y. Lu, F. Yu, J. Hu, Liu J. Appl. Catal. A 429-430 (2012) 48-58.

[4] Y. Lu, B. Cao, F. Yu, J. Liu, Z. Bao, J. Gao. ChemCatChem 6 (2014) 473-478.

[5] Q. Yan, F. Yu, J. Liu, J. Street, J. Gao, Z. Cai, J. Zhang. Bioresour. Technol. 127 (2013) 281-290.

[6] M.E. Dry. Catal Today 71 (2002) 227-241.

[7] J. Gao, B. Wu, L. Zhou, Y. Yang, X. Hao, J. Xu, Y. Xu, Y. Li. Ind. Eng. Chem. Res. 51 (2012) 11618-11628.

[8] J. Patzlaff, Y. Liu, C. Graffmann, J. Gaube. Appl. Catal. A 186 (1999)109-119.

[9] B.H. Davis. Catal. Today 141 (2009) 25-33.

[10] M.E. Dry. Appl. Catal. A 276 (2004) 1-3.

[11] E.D. Mark. Catal. Today 6 (1990) 183-206.

[12] C.D. Chang, W.H. Lang, A.J. Silvestri. J. Catal. 56 (1979) 268-273.

[13] K. Fujimoto, Y. Kudo, H.O. Tominaga. J. Catal. 87 (1984) 136-143.

[14] J. Ereña, J.M. Arandes, J. Bilbao, A.T. Aguayo, H.I. de Lasa. Ind. Eng. Chem. Res. 37 (1998) 1211-1219.

[15] S. Lögdberg, D. Tristantini, Ø. Borg, L. Ilver, B. Gevert, S. Järås, E.A. Blekkan, A. Holmen. Appl. Catal. B 89 (2009) 167-182.

[16] X. Huang, B. Hou, J. Wang, D. Li, L. Jia, J. Chen, Y. Sun. Appl. Catal. A 408 (2011) $38-46$. 
[17] F. Simard, U.A. Sedran, J. Sepúlveda, N.S. Fígoli, H.I. de Lasa. Appl. Catal. A 125 (1995) 81-98.

[18] R. Ravishankar, M.M. Li, A. Borgna. Catal. Today 106 (2005) 149-153.

[19] V.M. Mysov, S.I. Reshetnikov, V.G. Stepanov, K.G. Ione. Chem. Eng. J 107 (2005) 6371.

[20] J. Ereña, J.M. Arandes, J. Bilbao, M. Olazar, H.I. de Lasa. J. Chem. Technol. Biotechnol. 72 (1998) 190-196.

[21] S. Zaman, K.J. Smith. Catal. Rev. 54 (2012) 41-132.

[22] Y. Avila, C. Kappenstein, S. Pronier, J. Barrault. Appl. Catal. A 132 (1995) 97-109. [23] V.T.T. Ha, L.V. Tiep, P. Meriaudeau, C. Naccache. J. Mol. Catal. A 181 (2002) 283290.

[24] Y.O. Kim, R.W. Borry, E. Iglesia. J. Ind. Eng. Chem. 6 (2000) 72-78.

[25] A.A. Rownaghi, J. Hedlund. Ind. Eng. Chem. Res. 50 (2011) 11872-11878.

[26] Q. Zhang, J. Kang, Y. Wang. ChemCatChem 2 (2010) 1030-1058.

[27] A. Jess, R. Popp, K. Hedden. Appl. Catal. A 186 (1999) 321-342.

[28] R. Ohnishi, S. Liu, Q. Dong, L.Wang, M. Ichikawa. J. Catal. 182 (1999) 92-103.

[29] S. Liu, L. Wang, R. Ohnishi, M. Ichikawa. J. Catal. 181 (1999) 175-188.

[30] S. Liu, A. C. Gujar, P. Thomas, H. Toghiani, M.G. White. Appl. Catal. A 357 (2009) $18-25$.

[31] L. Wei, A. Thomasson, M. Bricka, R. Sui, J. Wooten, E. Columbus. Trans. ASABE 52 (2009) 21-37.

[32] M.H. Rafiq, H. A. Jakobsen, R. Schmid, J.E. Hustad. Fuel Process. Technol. 92 (2011) 893-907.

[33] A. Jess, R. Popp, K. Hedden. Appl. Catal. A 186 (1999) 321-342. 
[34] N. Tien-Thao, M. Hassan Zahedi-Niaki, H. Alamdari, S. Kaliaguine. J. Catal. 245 (2007) 348-357.

[35] J.M. Parera, N.S. Figoli, E.M. Traffano, J.N. Beltramini, E.E. Martinelli. Appl. Catal. 5 (1983) 33-41.

[36] L. Chen, L. Lin, Z. Xu, T. Zhang, X. Li. Catal. Lett. 39 (1996) 169-172.

[37] S. Li, C. Zhang, Q. Kan, D. Wang, T. Wu, L. Lin. Appl. Catal. A 187 (1999) 199-206.

[38] W. Zhang, X. Bao, X. Guo, X. Wang. Catal. Lett. 60 (1999) 89-94.

[39] S.P.R. Katikaneni, J.D. Adjaye, R.O. Idem, N.N. Bakhshi. Ind. Eng. Chem. Res. 35 (1996) 3332-3346.

[40] Y. Xu, S. Liu, X. Guo, L. Wang, M. Xie. Catal. Lett. 30 (1994) 135-149.

[41] L. Su, L. Liu, J. Zhuang, H. Wang, Y. Li, W. Shen, Y. Xu, X. Bao. Catal. Lett. 91 (2003) $155-167$.

[42] J. Shu, A. Adnot, B.P.A. Grandjean. Ind. Eng. Chem. Res. 38 (1999) 3860-3867.

[43] S. Masiero, N. Marcilio, O. Perez-Lopez. Catal. Lett. 131 (2009) 194-202.

[44] F.G. Botes, W. Böhringer. Appl. Catal. A 267 (2004) 217-225.

[45] W. Liu, Y. Xu, S. Wong, L. Wang, J. Qiu, N. Yang. J. Mol. Catal. A 120 (1997) 257-265.

[46] M. Ramos, D. Ferrer, E. Martinez-Soto, H. Lopez-Lippmann, B. Torres, G. Berhault, R.R. Chianelli. Ultramicroscopy 127 (2013) 64-69.

[47] J. He, Z. Liu, Y. Yoneyama, N. Nishiyama, N. Tsubaki. Chem. A Eur. J. 12 (2006) 8296-8304.

[48] D. Ma, D. Wang, L, Su, Y. Shu, Y. Xu, X. Bao. J. Catal. 208 (2002) 260-269.

[49] A. Nakhaei Pour, S.M.K. Shahri, Y. Zamani, M. Irani, S. Tehrani. J. Nat. Gas Chem. 17 (2008) 242-248.

[50] Q. Yan, P.T. Doan, H. Toghiani, A.C. Gujar, M.G. White. J. Phys. Chem. C 112 (2008) $11847-11858$. 
[51] X. Li, K. Asami, M. Luo, K. Michiki, N. Tsubaki, K. Fujimoto. Catal. Today 84 (2003) $59-65$.

[52] C.A. Mullen, A.A. Boateng. Fuel Process. Technol. 91 (2010) 1446-1458.

[53] R. Lu, S. Purushothama, X. Yang, J. Hyatt, W. Pan, J.T. Riley, W.G. Lloyd. Fuel Process. Technol. 59 (1999) 35-50.

[54] V. Udaya, S. Rao, R. J. Gormley. Catal. today 6 (1990) 207-234.

[55] S. Liu, R. Ohnishi, M. Ichikawa. J. Catal. 220 (2003) 57-65.

[56] M. Dry. Stud. Surf. Sci. Catal. 152 (2004) 196-257.

[57] D. Xu, H. Duan, W. Li, H. Xu. Energy Fuels 20 (2006) 955-958. 